\title{
Laboratory investigations of the impact of mineral dust aerosol on cold cloud formation
}

\author{
K. A. Koehler ${ }^{1}$, S. M. Kreidenweis ${ }^{1}$, P. J. DeMott ${ }^{1}$, M. D. Petters ${ }^{1, *}$, A. J. Prenni ${ }^{1}$, and O. Möhler ${ }^{2}$ \\ ${ }^{1}$ Department of Atmospheric Science, Colorado State University, Fort Collins, CO, 80523, USA \\ ${ }^{2}$ Institute for Meteorology and Climate Research, Karlsruhe Institute of Technology, Germany \\ *now at: Department of Marine Earth and Atmospheric Sciences, North Carolina State University, Raleigh, NC, 27695, USA
}

Received: 10 August 2010 - Published in Atmos. Chem. Phys. Discuss.: 17 August 2010

Revised: 10 November 2010 - Accepted: 30 November 2010 - Published: 15 December 2010

\begin{abstract}
Dust particles represent a dominant source of particulate matter (by mass) to the atmosphere, and their emission from some source regions has been shown to be transported on regional and hemispherical scales. Dust particles' potential to interact with water vapor in the atmosphere can lead to important radiative impacts on the climate system, both direct and indirect. We have investigated this interaction for several types of dust aerosol, collected from the Southwestern United States and the Saharan region. A continuous flow diffusion chamber was operated to measure the ice nucleation ability of the dust particles in the temperature range of relevance to cirrus and mixedphase clouds $\left(-65<T<-20^{\circ} \mathrm{C}\right)$. In most experiments, particles were size selected using a differential mobility analyzer prior to sampling to give information on heterogeneity of the sample with size, generally in the range of diameters $100-400 \mathrm{~nm}$. All dust nucleated ice heterogeneously in the deposition mode colder than about $-40^{\circ} \mathrm{C}$, but required droplet activation in the exclusively heterogeneous ice nucleation regime warmer than $-36^{\circ} \mathrm{C}$. Ice nucleated on $1 \%$ of dry generated dust particles of a given type at a similar relative humidity with respect to ice irrespective of temperature between -60 and $-40^{\circ} \mathrm{C}$, however differences in relative humidity for ice nucleation was observed between the different dust types. The Saharan dust types exhibited a dependency on particle size below $500 \mathrm{~nm}$. Additional data were collected during the International Workshop on Comparing Ice Nucleation Measurement Systems (ICIS, 2007) which indicated that ice nucleation on larger, polydisperse dust particles occurs at warmer temperatures than found for
\end{abstract}

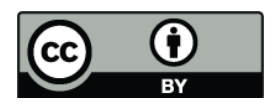

Correspondence to: K. A. Koehler (kirsten.koehler@colostate.edu) the smaller particles. When particles were coated with secondary organic aerosol (SOA) species, higher relative humidity was required for ice nucleation below $-40^{\circ} \mathrm{C}$, similar to that required for homogeneous nucleation of sulfates. However, ice nucleation was still observed on SOA-coated dust at warmer temperatures than are required for homogeneous nucleation of sulfates, indicating that condensation freezing occurs without any apparent deactivation for temperatures between -25 and $-35^{\circ} \mathrm{C}$.

\section{Introduction}

The Saharan desert contributes the largest concentrations of dust to the atmosphere (Swap et al., 1996; D'Alemeida, 1986). Most of the North African dust emissions are known to come from localized depressions such as the Bodélé depression, which is the remains of Mega-Lake Chad (Giles, 2005). At points in the past when the Saharan region was wetter, such as the Holocene pluvial during the Last Glacial Maximum, this lake contained water and diatoms thrived. Diatoms are unicellular organisms with a cell wall composed of $\mathrm{SiO}_{2}$. As the lake dried out, sediments contributed by these species were left behind which are now emitted as dust (Washington et al., 2006). Another large North African source area is a region covering eastern Mauritania, western Mali and southern Algeria (Goudie and Middleton, 2001). Both of these regions have little impact from anthropogenic activities. This dust can contribute to cloud condensation nuclei (CCN), giant CCN (GCCN), and ice nuclei (IN) concentrations while suspended in the atmosphere.

Measuring the conditions at which aerosols initiate ice formation in the atmosphere is important for global modeling. For temperatures colder than about $-36^{\circ} \mathrm{C}$,

Published by Copernicus Publications on behalf of the European Geosciences Union. 
homogeneous freezing nucleation rates increase, leading to freezing of dilute cloud droplets and haze particles containing hygroscopic material. In contrast, IN are typically insoluble and provide a surface for heterogeneous ice nucleation; their activity depends on size, temperature, and relative humidity (Pruppacher and Klett, 1997). IN can induce glaciation in clouds at any temperature below freezing via one or more mechanisms. For example, vapor can deposit as ice directly on an aerosol surface by deposition nucleation or aerosols can take up water and activate to liquid droplets with the insoluble material subsequently initiating freezing through condensation or immersion freezing. Recent studies have suggested that dust from arid regions can influence the microphysics of warm and cold cloud formation worldwide (Twohy et al., 2009; DeMott et al., 2003b; Sassen, 2002; Mahowald and Kiehl, 2003; Stith et al., 2009; Min et al., 2009). Laboratory studies confirm the ability of Saharan dust to nucleate ice at relative humidities with respect to water that are up to $20 \%$ lower than those required for homogeneous freezing of background sulfate aerosols at low temperatures (Möhler et al., 2006; Field et al., 2006; Kanji and Abbatt, 2006); these studies also demonstrate heterogeneous ice nucleation ability to temperatures at least as warm as $-20^{\circ} \mathrm{C}$. DeMott et al. (2003b) measured ice nuclei (IN) concentrations up to $0.3 \mathrm{~cm}^{-3}$, at $86 \%$ relative humidity with respect to water $\left(\mathrm{RH}_{w}\right)$ at $-36^{\circ} \mathrm{C}$, an observation that is only explicable by the presence of highly efficient IN in the Saharan dust plumes sampled near Florida. Sassen et al. (2003) found that Saharan dust was able to glaciate clouds at temperatures as warm as $-5.2{ }^{\circ} \mathrm{C}$. However, Ansmann et al. (2009) found that mid level clouds near Cape Verde typically transitioned to the ice phase for temperatures colder than $\sim-15^{\circ} \mathrm{C}$ and Ansmann et al. (2008) found that clouds were rarely glaciated at temperatures warmer than $-20^{\circ} \mathrm{C}$ from lidar measurements in Morocco. Both areas are frequently influenced by an elevated Saharan dust layer. Further, their observations showed that liquid phase clouds were always required before significant ice crystal concentrations developed, suggesting that the impact of deposition freezing in this temperature regime is limited. These observations imply that dust, uncoated or with various types of coatings, can contribute to different heterogeneous freezing types under certain temperature and relative humidity conditions.

Dust particles are known to be lofted to high altitudes at times, especially from Asian sources (Pratt et al., 2009; Uno et al., 2009). Parcel trajectory studies suggest that in many cases the particles reaching cirrus altitudes have been through a warmer cloud process beforehand and may contain coatings (Wiacek and Peter, 2009). In cirrus clouds forming in situ at high altitudes, a small concentration of IN $\left(<100 \mathrm{~L}^{-1}\right)$ that activate at ice supersaturations lower than required for homogeneous nucleation can have a large impact on cloud particle size distributions (DeMott et al., 1997). If a small fraction of the dust particles can nucleate ice at relative humidity with respect to ice $\left(\mathrm{RH}_{i}\right)$ below the homogeneous freezing threshold of the constituents that make up the majority of the particles (e.g. sulfates), then these few ice crystals will start to grow rapidly due to the supersaturation with respect to ice that exists in the upper troposphere. The liquid haze particles will start to lose water to these crystals and a distribution of very few, but large ice crystals will result, particularly at low updraft velocity conditions (Lin et al., 2002). In contrast, in the absence of these active dust particles, the cloud distribution would be comprised of a large number of small crystals formed via homogeneous nucleation. These two impacts would produce cloud types with different radiative properties and potentially different lifetimes (Murray et al., 2010b). At warmer temperatures, Lohmann and Diehl (2006), using their parameterization of heterogeneous ice nucleation, found that dust can have a significant impact on the liquid water path, cloud lifetime, precipitation rate and top of the atmosphere radiation. Further, they found significant differences in these properties if the dust was assumed to be composed of kaolinite or montmorillonite, two common mineral types found in atmospheric dust, due to small changes in the activation behavior between these species. Likewise, some laboratory studies indicate that there should be significant differences in the onset conditions of ice formation for different dusts depending on their mineralogical composition, suggesting that variations in mineral components could affect cloud impacts (Zimmerman et al., 2008; Murray et al., 2010a).

In this study, we attempt to constrain the fraction of mineral dust particles active as IN as a function of temperature, ice saturation ratio, and particle size (from $0.2-\sim 1.0 \mu \mathrm{m}$ ) for three dust samples. Two samples are from the North African region while the third is a commercially-produced product (Arizona Test dust) milled from Arizona desert sand. Many of the experiments were performed at Colorado State University (CSU) and additional studies extending to larger particle sizes were completed in collaboration with the International Workshop on Comparing Ice Nucleation Measurement Systems (ICIS, 2007) at the Institute for Meteorology and Climate Research at the Karlsruhe Institute of Technology in Karlsruhe, Germany (DeMott et al., 2008; Möhler et al., 2008b). Finally, size-selected Arizona Test dust was coated with secondary organic material, and the influence of this coating on the freezing behavior of the dust was determined.

\section{Experimental}

\subsection{Sample description}

We examined samples collected from the surface soil layer from two locations in the Saharan region. The first was collected near the town of Mala on the Canary Island of Lanzarote (hereafter, CID). While this island is not a major source of dust to the atmosphere, it is in the path of dust transport from the African continent and receives large annual 
deposits of Saharan dust, and presumably has for thousands of years. The most intense region of Saharan dust transport is between $10^{\circ}-25^{\circ} \mathrm{N}$ and shifts with season; Lanzarote, at $29^{\circ} \mathrm{N}$, is in the primary dust path during July, August and September (Goudie and Middleton, 2001). However, Saharan dust transport can also occur in the Northern Hemisphere winter, and persists over $30 \%$ of that season (Criado and Dorta, 2003). The CID sample also likely contains beach sand and small ancient coral. No processing or sieving of the sample was done prior to experiments.

The second surface sample was collected outside Cairo, Egypt (hereafter, SD). Studies have been performed on this sample previously at the Aerosol Interactions and Dynamics in the Atmosphere (AIDA) cloud chamber facility (Field et al., 2006; Linke et al., 2006; Möhler et al., 2006; Connolly et al., 2009). Prior to being shipped to our laboratory it was sieved to contain only particles smaller than $75 \mu \mathrm{m}$. Although the region around Cairo is also not considered a dominant source of dust to the atmosphere, Sharav cyclones occur during the spring which can transport large quantities of dust (Kubilay et al., 2000; Alpert and Ganor, 2001). Alpert and Ganor (2001) reported that during an extremely large dust event on 15-17 March 1998 in Israel, concentrations of particulate matter with diameters less than $10 \mu \mathrm{m}$ $\left(\mathrm{PM}_{10}\right)$ exceeded $8000 \mu \mathrm{g} \mathrm{m}^{-3}$. Snow also occurred during the dust washout, an extremely rare event in mid-March (Alpert and Reisin, 1986). While our samples are not from regions expected to be the primary sources of North African dust to the atmosphere, Schütz and Sebert (1987) found that the mineralogical compositions of aeolian and surface mineral dust with diameters less than $10 \mu \mathrm{m}$ are quite homogeneously mixed throughout North Africa and are in crustal proportions. The chemical composition of mineral dust is comprised of a variety of clay species that include oxides of silicon, aluminum, calcium, magnesium, iron, potassium, and other salts and metal species. Detailed chemical analysis for a different subset of the SD was reported by Linke et al. (2006).

Arizona Test dust (hereafter ATD), on the other hand, is a commercially available product (Powder Technologies, Inc.) with low soluble mass fraction. The three samples studied in this work were also examined by Koehler et al. (2009) to determine the hygroscopicity and CCN activity of these particles. All three dusts were found to have low hygroscopicity below water saturation, yet were able to serve as $\mathrm{CCN}$ at lower supersaturations than similarly-sized insoluble, wettable particles. CCN activation of these particles was best represented assuming $\sim 2 \%$ by mass soluble coating on the surface of the particles, if the soluble material were to behave as sulfuric acid.

\subsection{Aerosol generation}

Previous studies have shown that suspending mineral dust samples in water prior to reaerosolization can redistribute soluble material among the insoluble cores in an unrepresentative way and lead to enhanced hygroscopicity and CCN activation and a reduction in the ability of the particles to serve as heterogeneous IN (Koehler et al., 2007; Koehler et al., 2009). Therefore, in this study, we have primarily presented results of the ice nucleation behavior of particles generated from bulk powders without submersion in water, using a fluidized bed. Conditions for ice nucleation of the atomized dust suspensions in water (ATD and CID only) are available in Koehler (2008). In the fluidized bed (Prenni et al., 2000), bulk powder is mixed with bronze beads (diameter $\sim 40 \mu \mathrm{m}$ ) in a cylindrical bed. Air flows through filters located below the bed, causing a pressure drop which fluidizes the mixture, and dust particles are carried out of the fluidized bed for particle analysis. The fluidized bed is capable of producing particles from $\sim 0.1$ to several micrometers. During ICIS, a rotating brush generator (RGB 1000, Palas) was used to dry disperse the bulk particles. It is expected that no differences in particle properties would be observed for these two generation methods.

All experiments performed at CSU used a Differential Mobility Analyzer (DMA, TSI Model 3071A) to produce a quasi-monodisperse aerosol flow. Due to low number concentrations of the resuspended aerosol, it was often necessary to use flow ratios (sheath:aerosol) as low as 7.0:2.5 lpm in the DMA for CID and SD. For a flow ratio of 7.0:2.5, selection of a nominal $200 \mathrm{~nm}$ particle size can produce a sample stream containing singly-charged particles having diameters between $162-269 \mathrm{~nm}$, and selection of a nominal $400 \mathrm{~nm}$ particle size will produce a sample stream containing singlycharged particles having diameters between $323-557 \mathrm{~nm}$. A flow ratio of 5:1 was used for size selection of ATD particles, yielding somewhat sharper size selection around the nominal size (e.g. a nominal $400 \mathrm{~nm}$ particle size will produce a sample stream containing singly-charged particles having diameters between $351-472 \mathrm{~nm}$ ). When selecting larger particles with the DMA, there is also a higher percentage of multiply charged, larger particles in the sample stream. Based on the size distributions reported during the ICIS campaign (see below) and for these flow ratios, approximately $60-66 \%$ of particles in the aerosol stream will be singly-charged particles with the size ranges as indicated above. However, 30-33\% of the particles will be doubly-charged, larger particles (up to 370,592 and $820 \mathrm{~nm}$ for nominally sized 200, 300, and 400 $\mathrm{nm}$ particles, respectively, at 5:1 sheath:aerosol flow ratio) and $2-6 \%$ of the particles will have three charges (up to 501, 819 and $951 \mathrm{~nm}$ for nominally sized 200, 300, and $400 \mathrm{~nm}$ particles, respectively, at 5:1 sheath:aerosol flow ratio). Thus low activation fractions may result if only the largest, multiply charged particles in the aerosol stream activate.

One goal addressed via the ICIS study was to determine the ice nucleation behavior of polydisperse aerosol containing larger particles than were examined during the CSU laboratory studies. The particle size distributions were roughly log-normal with geometric mean diameters between 
$0.17-0.22 \mu \mathrm{m}$ and typical $\sigma_{g}$ of $1.7-1.8$ for the three dust samples. An impactor used during particle generation for ICIS 2007 removed most supermicron particles (Möhler et al., 2008b), and an additional impactor was placed on the CFDC inlet to remove particles larger than $1.2 \mu \mathrm{m}$ (50\% efficiency) for reasons discussed below.

\subsection{Continuous flow diffusion chamber}

The experimental method is similar to that of Koehler et al. (2007). Briefly, the continuous flow diffusion chamber (CFDC) allows real time measurement of IN concentrations from an aerosol flow. Two models of the instrument were used in this work, a laboratory unit and an aircraft unit, both of which are modified versions of the original chamber design described by Rogers (1988). The laboratory unit is generally operated between $-60 \leq T \leq-35^{\circ} \mathrm{C}$, while the aircraft unit (Rogers et al., 2001) was optimized for use in aircraft studies and generally operates between $-40 \leq T \leq-10^{\circ} \mathrm{C}$. Each system consists of two ice coated concentric copper cylinders with a $\sim 1.1 \mathrm{~cm}$ gap between the surfaces. Both walls are cooled to the operating conditions, with one wall (generally the outer wall) several degrees warmer than the other, inducing a supersaturation with respect to ice between the surfaces. The aerosol enters the chamber between two particle-free sheath flows and is generally $10 \%$ of the total flow $(\sim 12 \mathrm{lpm})$. By increasing the temperature gradient, the $\mathrm{RH}_{i}$ is increased slowly until a condition is achieved for which a threshold fraction of the aerosol particles nucleate ice crystals. The temperature the aerosol lamina is exposed to stays roughly constant throughout an experiment. The laboratory unit also has a copper flow tube precooler unit, which reduces the sample temperature and lowers the water vapor pressure to ice saturation at $\sim-27^{\circ} \mathrm{C}$ (DeMott et al., 2009a). Uncertainty of $\mathrm{RH}_{w}$ varies with temperature, and is larger for colder temperatures, with a value of $3 \%$ characterizing temperatures below $-30^{\circ} \mathrm{C}$ (Richardson, 2009; DeMott et al., 2009a). The presence of ice crystals is determined using an optical particle counter (OPC, Climet Model 7350A, 3100). All particles are binned by size and a threshold size is determined such that all larger particles are assumed to be ice. The use of optical detection to determine the presence of ice crystals limits the size of dust particles that can be examined to smaller than $\sim 1.6 \mu \mathrm{m}$. For larger sizes, our OPC detection method is not able to distinguish between large unactivated aerosol and ice crystals.

To ensure that large particles counted in the OPC are indeed ice crystals and not large activated liquid droplets when operating the aircraft unit for mixed-phase supercooled cloud conditions $\left(\mathrm{RH}_{w}>100 \%\right)$, an evaporation region is maintained in the lower $1 / 3$ of the chamber by setting the ice wall temperatures to be equal to achieve ice saturation conditions. Water droplets entering this region will evaporate to sizes smaller than the determined threshold size for the OPC. We note that the evaporation region of the aircraft CFDC used in this work differs from that of Rogers et al. (2001), which used a warm wall section covered by a hydrophobic material to induce evaporation. For sufficiently high supersaturations with respect to water, it is not possible to completely evaporate large water drops in the residence time of the evaporation region, resulting in an upper $\mathrm{RH}_{w}$ limit for which ice crystals can be unambiguously determined (Rogers et al., 2001). This upper $\mathrm{RH}_{w}$ limit generally varies between $108-112 \% \mathrm{RH}_{w}$ for the aircraft CFDC as configured in this work. This upper limit is equivalent to what Welti et al. (2009) referred to, and we will refer to hereafter, as the "water breakthrough" $\mathrm{RH}_{w}$. We used the measured droplet formation by SD dust, as a function of temperature, to determine this threshold during the ICIS campaign for $T>-35^{\circ} \mathrm{C}$. This region is indicated on all figures presenting ice nucleation conditions as a gray shaded region. For $-38^{\circ} \mathrm{C}<T<-33^{\circ} \mathrm{C}$, a transition region for which the state of the particles cannot be unambiguously determined is shaded in lighter gray. In this region, measured ice crystal concentrations may also be influenced by the presence of liquid droplets freezing homogeneously as they begin to evaporate after entering the lower temperature droplet evaporation region. The laboratory unit does not possess an evaporation region and thus if water saturation is exceeded, the OPC cannot distinguish if the grown particles are liquid or ice phase.

\subsection{Coating system}

The coating system consisted of a mixing tank $(11.5 \mathrm{~L})$ with controlled ozone, $\alpha$-pinene and dry generated ATD aerosol flows. Ozone is known to react with $\alpha$-pinene gas to form secondary organic products with low enough vapor pressures to partition to the particle phase (Docherty et al., 2005). Oxidation products of terpenes, such as $\alpha$-pinene, contribute substantially to the organic carbon aerosol in the atmosphere. Heald et al. (2006) estimated the source of SOA aerosol from terpenes to be $0.81 \mathrm{Tg} \mathrm{C}$ over North America during JulyAugust, twice as large as the SOA source due to isoprene oxidation. The entire ATD particle distribution (i.e., no size cuts after generation by the fluidized bed) was sent to the mixing tank to provide as much aerosol surface area as possible to take up organic vapors and prevent nucleation of pure secondary organic aerosol (SOA) particles. The water uptake of SOA generated in this manner (Petters et al., 2009b; Wex et al., 2009), as well as the chemical properties (Poulain et al., 2010) are known to be similar to those generated from the reaction of $\alpha$-pinene with ozone in a smog chamber, yet it is uncertain if SOA generated in this manner is atmospherically relevant. Pure SOA from oxidation of $\alpha$-pinene is not expected to nucleate ice heterogeneously (Prenni et al., 2009; Möhler et al., 2008a), and so any measured impacts on ice nucleation of dusts should result due to alterations to the dust surface and changes in the hygroscopicity of the particles. Recent studies suggest that exposure of IN to a high ozone environment neither inhibits nor aids in the ice nucleating 
properties of the aerosol (R. Sullivan, personal communications, 2010).

We hoped to estimate the SOA mass deposited on the particles via growth factor or CCN measurements, but low number concentrations made these measurements impossible. Therefore the thickness of the coating is unknown. Sizeselected ice nucleation measurements (using DMA flow ratios of 9.6:2.6) are presented, where the size of the selected particles includes the dust and the coating.

\section{Results and discussion}

In each of Figs. 1-5, the temperature and $\mathrm{RH}_{i}$ conditions for ice formation (either $1 \%$ or $5 \%$ of particles nucleating ice) on mineral dust particles is shown.

For the ATD and CID results at $T \leq-40{ }^{\circ} \mathrm{C}$, all symbols represent the average of at least three measurements with error bars indicating the $95 \%$ confidence interval. There was a limited mass of the SD for examination which made it impossible to perform repetitions of the size-resolved experiments, so individual data points are shown. For all samples at $T>-40^{\circ} \mathrm{C}$, individual data points are shown, as a strong dependence on temperature was observed, and repeat measurements often varied by $>1{ }^{\circ} \mathrm{C}$. The conditions for homogeneous nucleation of $200 \mathrm{~nm}$ ammonium sulfate particles, according to the parameterization developed by Koop et al. (2000), is also shown in the figure. Homogeneous nucleation is only a weak function of size and thus the homogeneous freezing representations for $200-400 \mathrm{~nm}$ particles would fall nearly on top of one another for the $\mathrm{RH}_{i}$ scale on these figures $\left(\triangle \mathrm{RH}_{i}=1.5 \%\right.$ between 200 and $400 \mathrm{~nm}$ particles at $T=-60^{\circ} \mathrm{C}$ ). For dust particles to have a significant impact on cold cloud formation, it is necessary that the dust particles initiate the ice phase at lower humidities or warmer temperatures than are required for homogeneous nucleation of the background aerosol. At temperatures warmer than $-40^{\circ} \mathrm{C}$, the shaded water-breakthrough region is well above water saturated conditions, so that if particles require these conditions for ice nucleation, they are unlikely to contribute to ice formation in the atmosphere.

\subsection{Arizona Test dust}

Conditions for ice nucleation on ATD particles are summarized in Fig. 1. All points represent the conditions for which $1 \%$ of the particles nucleated ice. Aerosol diameter is denoted by color as indicated in the figure caption. Under many conditions, ATD readily served as an IN, with particles larger than $200 \mathrm{~nm}$ freezing below $80 \% \mathrm{RH}_{w}$ at $T<-40{ }^{\circ} \mathrm{C}$, and little dependence of the $\mathrm{RH}_{i}$ for ice nucleation with temperature. There was also a modest size dependence, with larger particles nucleating more efficiently, although the significance of this result is complicated by the uncertainty in $\mathrm{RH}_{w}$ in the instrument $( \pm 3 \%)$. As the temperature increased

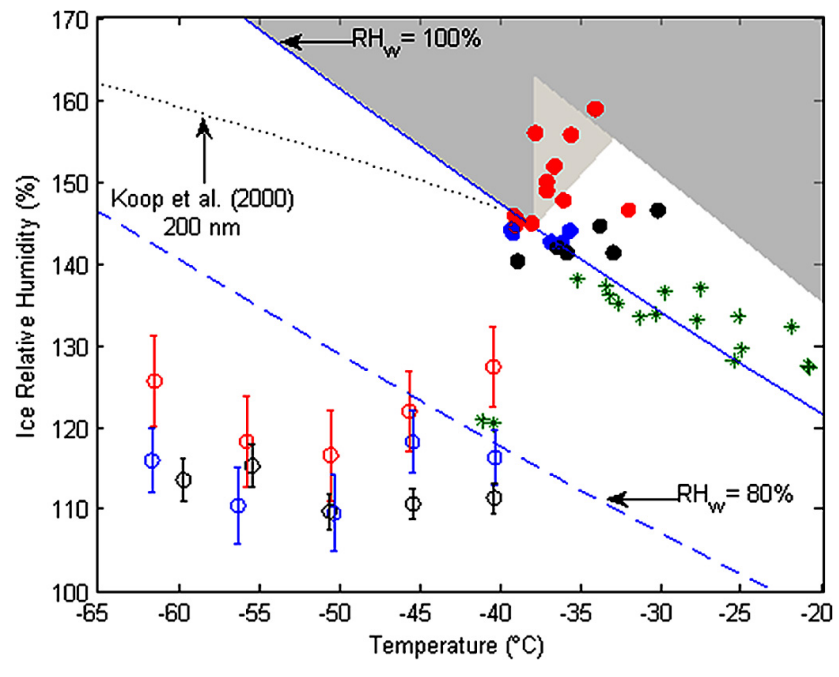

Fig. 1. Conditions for ice nucleation on $1 \%$ of ATD particles as a function of temperature for sizes: $200 \mathrm{~nm}$ (red), $300 \mathrm{~nm}$ (blue), $400 \mathrm{~nm}$ (black). Open symbols represent data collected with the laboratory unit and filled symbols represent data collected with the aircraft unit. Green stars represent conditions for ice nucleation on $1 \%$ of polydisperse ATD particles during ICIS. The dark gray shading indicates the region where droplets are known to be counted by the OPC in the CFDC systems. The light gray shading indicates the transition where the state of the particle counted by the OPC is ambiguous. Water saturation, $\mathrm{RH}_{w}=80 \%$ and the conditions for which $200 \mathrm{~nm}\left(\mathrm{NH}_{4}\right)_{2} \mathrm{SO}_{4}$ particles nucleate ice according to Koop et al. (2000) are indicated in the figure for reference.

above $-40^{\circ} \mathrm{C}$, the particles rapidly lost their ability to initiate the ice phase within the deposition nucleation regime, nucleating ice only at water supersaturated conditions, suggesting a shift to condensation freezing. We must note that the specific $\mathrm{RH}_{w}$ condition for $1 \%$ freezing carries less distinct meaning for CFDC measurements in the water supersaturated regime because elevated $\mathrm{RH}_{w}$ conditions (by $5 \%$ or more) are required to dilute activated water droplets sufficiently (in the short CFDC growth times available) to overcome surface chemical influences on freezing of complex particles (Petters et al., 2009a; DeMott et al., 2010). Nevertheless, the fact that the polydisperse particles, which extended to $1 \mu \mathrm{m}$ diameter, indicated ice formation at the $1 \%$ freezing level at temperatures as warm as $-20^{\circ} \mathrm{C}$ suggests size effects for condensation freezing activity. We expect that the activation behavior of the polydisperse aerosol is driven by the largest particles in the distribution. As discussed, our results are limited to diameter $<1.2 \mu \mathrm{m}$, so we could not assess if still larger particles may nucleate ice to even warmer temperatures than observed in our studies.

Möhler et al. (2006) also studied ATD in clouds formed by expansion cooling in the AIDA cloud chamber. In those studies, a nearly lognormal distribution of dry-generated particles with a median diameter of $350 \mathrm{~nm}$ and a geometric standard deviation of 1.65 was used. Particles larger than $2 \mu \mathrm{m}$ were 
removed from the sample with an impactor for that study. Möhler et al. (2006) found over the range $-75 \leq T \leq-50^{\circ} \mathrm{C}$ the ATD particles nucleated ice in the same proportion at a nearly constant $\mathrm{RH}_{i}$, although nucleation onset (8\% of particles frozen) was observed at lower humidities than in our studies, between 101-110\% $\mathrm{RH}_{i}$. However, considering the size dependence found for freezing $\mathrm{RH}_{i}$ of the dry-generated particles in this study, it is probable that it was the largest particles in their distribution which nucleated ice first. Consistent with such a notion, Möhler et al. (2006) found 55\% of their particles, equivalent to all particles larger than $300 \mathrm{~nm}$ in their distribution, to nucleate ice at $-50^{\circ} \mathrm{C}$ for a maximum $\mathrm{RH}_{i}$ of $\sim 115 \%$; this is the approximate $\mathrm{RH}_{i}$ we observed to be required for freezing $300 \mathrm{~nm}$ particles.

Work by other researchers also suggests that larger ATD particles may be active as IN at warmer temperatures than observed in this work. Knopf and Koop (2006) examined ATD particles as large as $10 \mu \mathrm{m}$ using a low temperature stage method and found ice nucleation occurred at temperatures as warm as $-13^{\circ} \mathrm{C}$. Similar results were found by Kanji and Abbatt (2006) and Salam et al. (2006).

\subsection{Canary Island dust}

Ice nucleation measurements for CID are shown in Fig. 2. Each point indicates the conditions for which $5 \%$ of the particles nucleated ice. Due to lower number concentrations of re-aerosolized CID compared to ATD, it was necessary to use lower flow ratios in the DMA (7.0:2.5 lpm), yielding broader distributions around the selected diameter. This made it difficult to distinguish conditions for $1 \%$ activation for particles larger than $200 \mathrm{~nm}$ because of the influence of large dust and haze on the OPC signal, necessitating the $5 \%$ activation threshold. Data are shown by nominal diameter represented by color as for Fig. 1. As for ATD, ice nucleation conditions for dry-generated CID show very little dependence on $\mathrm{RH}_{i}$ for $T<-40^{\circ} \mathrm{C}$ and, despite the broader size cuts (and larger influence of multiply-charged, larger particles), a strong size dependence was observed. Since only $\sim 1.5 \%$ of the particles in the size distribution for the CID during the ICIS campaign consisted of particles larger than $550 \mathrm{~nm}$, it is not surprising that there is reasonable agreement at $-40^{\circ} \mathrm{C}$ for the two measurement systems $\left(\mathrm{RH}_{i}\right.$ and $T$ conditions during the ICIS campaign indicate where $1 \%$ of particles nucleated as ice crystals). All sizes showed ice nucleation at considerably lower ice supersaturations than are required for homogeneous freezing of ammonium sulfate at relevant temperatures. However, at $\sim-36^{\circ} \mathrm{C}$ the size dependence is no longer apparent, and water supersaturated conditions are required for ice formation at warmer temperatures via condensation freezing. For temperatures warmer than $-25^{\circ} \mathrm{C}$ ice nucleation was not observed for the limiting conditions required to define threshold ice formation by size-selected ( $5 \%$ freezing) or polydisperse ( $1 \%$ freezing) particles.

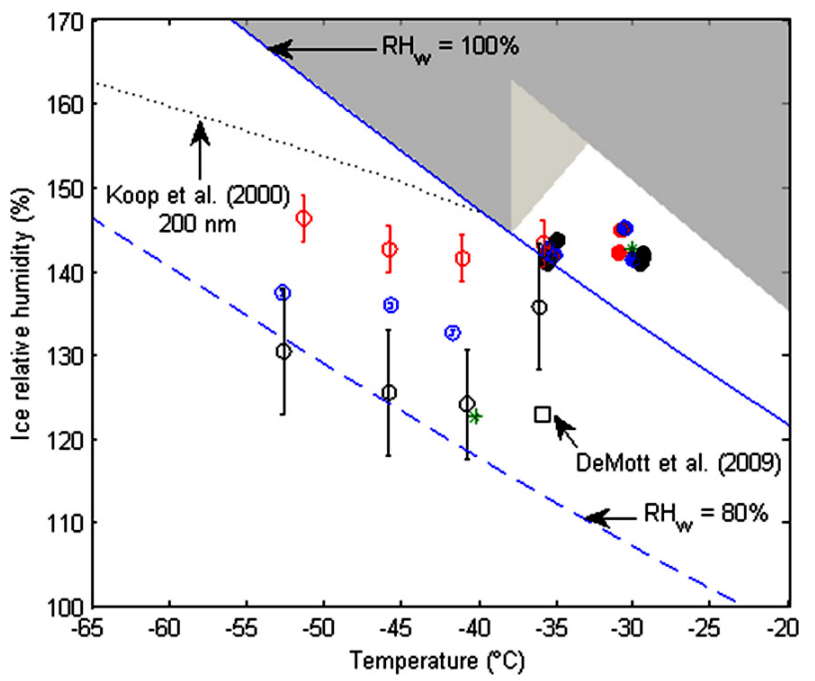

Fig. 2. Conditions for ice nucleation on $5 \%$ of CID particles as a function of temperature for sizes: $200 \mathrm{~nm}$ (red), $300 \mathrm{~nm}$ (blue), $400 \mathrm{~nm}$ (black). Open symbols represent data collected with the laboratory unit and filled symbols represent data collected with the aircraft unit. Green stars represent conditions for ice nucleation on $1 \%$ of polydisperse CID particles during ICIS. The dark gray shading indicates the region where droplets are known to be counted by the OPC in the CFDC systems. The light gray shading indicates the transition where the state of the particle counted by the OPC is ambiguous. Water saturation, $\mathrm{RH}_{w}=80 \%$ and the conditions for which $200 \mathrm{~nm}\left(\mathrm{NH}_{4}\right)_{2} \mathrm{SO}_{4}$ particles nucleate ice according to Koop et al. (2000) are indicated in the figure for reference.

Of all of the dust samples examined, the CID sample may be the most representative of settled Saharan dust after airborne transport. The values of $0.3 \mathrm{~cm}^{-3} \mathrm{IN}$ measured by DeMott et al. (2009b) in a Saharan dust layer $\left(T=-36^{\circ} \mathrm{C}\right.$ and $\mathrm{RH}_{i}=123 \%$ ) represented about $2 \%$ of the number concentrations of all particles larger than $500 \mathrm{~nm}$ (black square, Fig. 2). This is in reasonable agreement with the CID observations, being at the threshold for $5 \%$ of the $400 \mathrm{~nm}$ particles to freeze.

\subsection{Saharan dust}

Conditions required for ice nucleation on SD are shown in Fig. 3, and for the same reasons as described for the CID, represent $5 \%$ of the particles activating as IN. The labeling convention in Fig. 1 was used. Due to very low number concentrations of SD particles produced for these flow ratios (7.0:2.5 $\mathrm{lpm}$ ), additional series were added when flow ratios were 4.0:2.5 $\mathrm{lpm}$. At this flow ratio, when a nominal size of $600 \mathrm{~nm}$ was selected, singly-charged particles between $472-$ $860 \mathrm{~nm}$ exited the DMA. The $\mathrm{RH}_{i}$ and $T$ conditions for this set of experiments are shown in black squares. This experiment also demonstrates that the size dependence observed for $200-400 \mathrm{~nm}$ particles continues to larger sizes, at least for SD particles. 


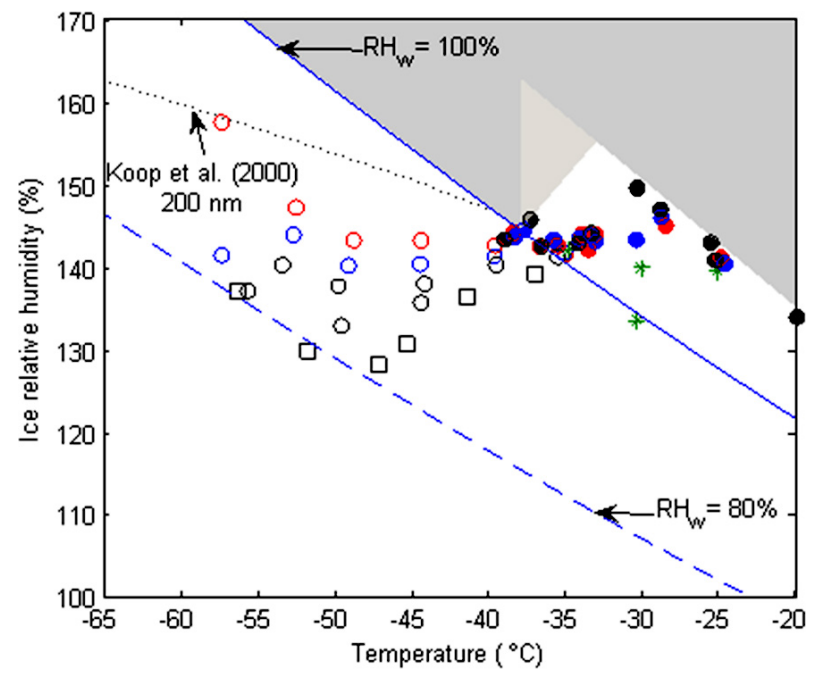

Fig. 3. Conditions for ice nucleation on $5 \%$ of SD particles as a function of temperature for sizes: $200 \mathrm{~nm}$ (red), $300 \mathrm{~nm}$ (blue), $400 \mathrm{~nm}$ (black circles) with flow ratios of 7.0:2.5 lpm in the DMA. Black squares are for $600 \mathrm{~nm}$ data with flow ratios of 4.0:2.5 lpm in the DMA. Points represent $5 \%$ of the particles activating as ice crystals. Open symbols refer to data collected with the laboratory unit, filled symbols refer to data collected in the aircraft unit. Green stars represent conditions for ice nucleation on $1 \%$ of polydisperse SD particles during ICIS. The dark gray shading indicates the region where droplets are known to be counted by the OPC in the CFDC systems. The light gray shading indicates the transition where the state of the particle counted by the OPC is ambiguous. Water saturation, $\mathrm{RH}_{w}=80 \%$ and the conditions for which $200 \mathrm{~nm}\left(\mathrm{NH}_{4}\right)_{2} \mathrm{SO}_{4}$ particles nucleate ice according to Koop et al. (2000) are indicated in the figure for reference.

As was seen for CID and ATD, little dependence of $\mathrm{RH}_{i}$ with decreasing temperature at $T<-40^{\circ} \mathrm{C}$ was observed for ice nucleation of the same fractions of particles. Also, at temperatures warmer than $-36^{\circ} \mathrm{C}$, water supersaturation was required to initiate the ice phase via condensation freezing nucleation. During ICIS, no measurements of SD at temperatures colder than $-40^{\circ} \mathrm{C}$ were performed for comparison to the size-resolved experiments, but the polydisperse SD distribution yields similar results as were found for the size resolved experiments at warmer temperatures. Ice nucleated by condensation/immersion freezing on $1 \%$ of polydisperse SD for temperatures as warm as $-25^{\circ} \mathrm{C}$.

Field et al. (2006), Möhler et al. (2006) and Connolly et al. (2009) studied ice nucleation of a different subset of the sample of SD provided to us, in AIDA chamber expansion experiments. Each study used a nearly lognormal distribution of particles with an average mean diameter of $0.35 \mu \mathrm{m}$ and an average standard deviation of 1.85 , with particles larger than $2 \mu \mathrm{m}$ removed by an impactor prior to entering the chamber. Möhler et al. (2006) provided onset (8\% of particles freezing) and maximum nucleated fractions and the corresponding ice supersaturation for which these occurred for a few cooling experiments in the cirrus temperature regime. They observed $8 \%$ freezing at $135 \% \mathrm{RH}_{i}$ and $24 \%$ freezing at $145 \% \mathrm{RH}_{i}$ at $-53{ }^{\circ} \mathrm{C}$. Our $5 \%$ freezing $\mathrm{RH}_{i}$ values for the 300 and $400 \mathrm{~nm}$ size-selected particles are in good agreement with the AIDA onsets at this temperature (Fig. 3). The maximum frozen fraction assessed at this temperature in our CFDC experiments was $\sim 20 \%$, occurring at $\sim 153 \%$ $\mathrm{RH}_{i}$ for 300 to $400 \mathrm{~nm}$ size selected particles, several percent $\mathrm{RH}_{i}$ higher than in AIDA studies. Field et al. (2006) report relative humidity conditions for which $\sim 0.5 \%$ (onset or minimum detection level) and $8 \%$ of the particles nucleated ice for several more AIDA experiments with SD in three narrow temperature regimes (c.f., Fig. 6 of Field et al., 2006); the $\mathrm{RH}_{i}$ values for these activation conditions bound the $5 \%$ freezing conditions of our size-selected particles in the -52 to $-54{ }^{\circ} \mathrm{C}$ range, and equate to our freezing relative humidity conditions in 4 of 5 their experiments at -36 to $-38^{\circ} \mathrm{C}$ ).

Field et al. (2006) also observed onset ice formation ( $\sim 0.5 \%$ freezing) of the SD particles nucleating ice in three experiments in the condensation freezing regime at -20 to $-22{ }^{\circ} \mathrm{C}$, consistent with only one of our experiments for nominal $400 \mathrm{~nm}$ particles. Connolly et al. (2009) found $1 \%$ of their Saharan dust particle distribution freezing at $-25^{\circ} \mathrm{C}$, more consistent with the majority of our experimental observations. Connolly et al. (2009) did observe much smaller numbers of ice crystals forming in their experiments as warm as $-20^{\circ} \mathrm{C}$. DeMott et al. (2010) show good agreement between the maximum condensation/immersion freezing fractions in AIDA expansions and CFDC measurements while sampling the same particle distributions at temperatures from -21 to $-26^{\circ} \mathrm{C}$ during ICIS.

Kanji and Abbatt (2006) examined a different Saharan dust sample on their cold stage system and found that ice nucleation occurred between $100<\mathrm{RH}_{i}<105 \%$ for temperatures between -13 to $-53{ }^{\circ} \mathrm{C}$. Their studies included particles as large as $5 \mu \mathrm{m}$. We expect differences in ice nucleation activity between our work and Kanji and Abbatt (2006) arise due to the larger particles used, the exposure to liquid water prior to freezing measurements, and possibly due to interactions with the substrate used for the cold stage measurements.

\subsection{Coated ATD}

The SOA-coated ATD had dramatically different freezing behavior as compared to the uncoated ATD particles at lower temperatures (Fig. 4). The conditions are shown for $1 \%$ of the particles nucleating ice crystals and each point from the laboratory unit (open symbols) is the average of three measurements with error bars indicating the confidence interval at the $95 \%$ level. Data collected with the aircraft unit (filled symbols) are shown as individual data points. The selected sizes are slightly different from those used for the uncoated cases. Red circles represent $160 \mathrm{~nm}$ particles, blue circles represent $250 \mathrm{~nm}$ and black circles represent $340 \mathrm{~nm}$ coated ATD. At $T<-40^{\circ} \mathrm{C}$, the coated ATD 


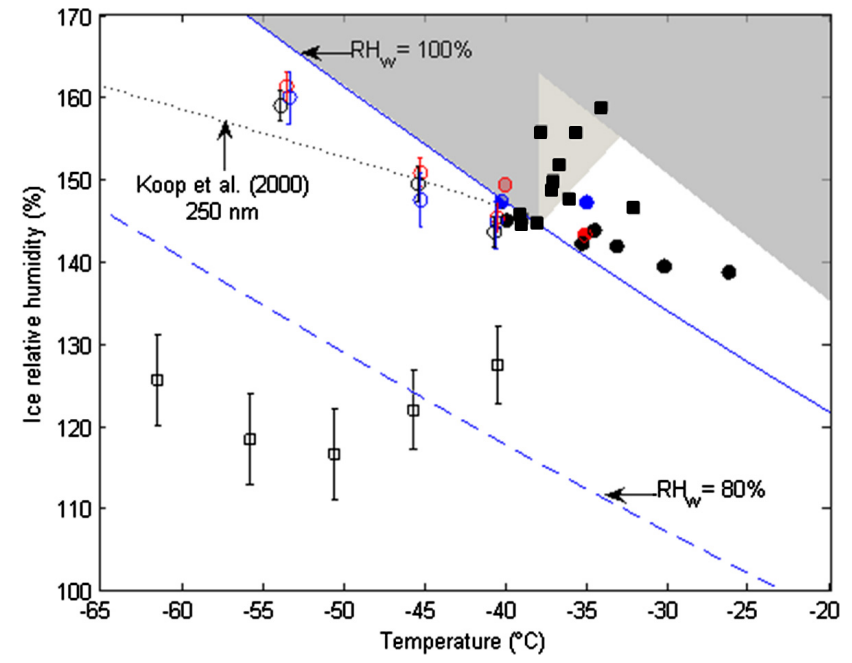

Fig. 4. Conditions for ice nucleation on $1 \%$ of SOA-coated ATD particles as a function of temperature for sizes: $160 \mathrm{~nm}$ (red), $250 \mathrm{~nm}$ (blue), $340 \mathrm{~nm}$ (black). Open symbols represent data collected with the laboratory unit and filled symbols represent data collected with the aircraft unit. Conditions for ice nucleation on $1 \%$ uncoated $200 \mathrm{~nm}$ ATD particles (black squares) are included for reference. The dark gray shading indicates the region where droplets are known to be counted by the OPC in the CFDC systems. The light gray shading indicates the transition where the state of the particle counted by the OPC is ambiguous. Water saturation, $\mathrm{RH}_{w}=80 \%$ and the conditions for which $250 \mathrm{~nm}\left(\mathrm{NH}_{4}\right)_{2} \mathrm{SO}_{4}$ particles nucleate ice according to Koop et al. (2000) are indicated in the figure for reference.

required relative humidities for freezing in near equivalence to those required for freezing solutes homogeneously, considering relative humidity uncertainties. The activation $\mathrm{RH}_{i}$ values exceeded those for uncoated particles by up to $40 \%$. Despite this impact within the homogeneous freezing temperature regime, coated ATD particles were capable of serving as immersion IN for $-40 \leq T \leq-25^{\circ} \mathrm{C}$. Since nucleation occurred at temperatures warmer than those for which homogeneous freezing can occur and SOA is not expected to act as a heterogeneous IN, the observed freezing must be due to the presence of the dust core. It also appears that the larger particles have ice nucleation activity via condensation/immersion freezing at warmer temperatures than do the smaller particles (no freezing was observed for particles less than $340 \mathrm{~nm}$ at temperatures warmer than $-35^{\circ} \mathrm{C}$ ), a trend also suggested for ice nucleation by uncoated dust particles during the ICIS campaign.

Möhler et al. (2008a) coated larger polydisperse ATD $\left(d_{g}=0.53 \mu \mathrm{m} ; s_{g}=1.28\right)$ with SOA in a very similar manner as was done in this study. They specify a $17 \mathrm{wt} \%$ SOA coating in their system. They performed measurements only at $\sim-65^{\circ} \mathrm{C}$, where they found $\sim 15 \%$ higher $\mathrm{RH}_{i}$ was required for heterogeneous ice nucleation on about $10 \%$ of the particles. A very high freezing fraction required raising $\mathrm{RH}_{w}$ above values required for homogeneous freezing of coatings and even above water saturation. Differences between their results and those presented here may depend on the thickness and uniformity of the SOA coating and particle sizes. Different SOA products may also be generated due to differences in $\alpha$-pinene to ozone ratios between the studies.

In the current study, it is unclear how thick the SOA coatings were. However, the inhibition of the deposition mode of ice nucleation indicates that a similar process occurred on the coated ATD particles as was observed for $200 \mathrm{~nm}$ sulfuric acid coated alumina silicate particles in the CFDC experiments of Archuleta et al. (2005). In that study, sulfate promoted a liquid layer covering the alumina-silicate substrate which was hypothesized to be detrimental to ice formation as compared to the hydrophobic surface (Bassett et al., 1970).

In contrast to the results of Archuleta et al. (2005) who examined coated submicron mineral dust constituents, Zuberi et al. (2002) who examined the freezing behavior of larger mineral dust inclusions in concentrated ammonium sulfate droplets (10-55 $\mu \mathrm{m})$, and Zobrist et al. (2008) whose studies included freezing of emulsions with distributions of included ATD, coating by SOA did not lead to a clearly detectable occurrence of heterogeneous freezing by the immersed single ATD particles as the $\mathrm{RH}_{w}$ was increased. Heterogeneous freezing was recognized in the studies of Zuberri et al. (2002), Archuleta et al. (2005), and Zobrist et al. (2008) by a clear reduction of the difference of water activity between the freezing conditions and the water activity of the solution in equilibrium with ice, compared to that required for homogeneous nucleation of the pure coating (Koop et al. 2000). For example, Zuberi et al. (2002) found a $\sim 6 \%$ reduction in $\mathrm{RH}_{w}$ ( $a_{w}$ is approximately equal to $\mathrm{RH}_{w}$ for particles greater than $200 \mathrm{~nm}$ ) for freezing compared to the homogeneous nucleation of pure ammonium sulfate particles. In the present study, there was no significant difference in the freezing conditions of the SOA coated ATD particles as compared to pure ammonium sulfate drops of similar size (the homogeneous freezing conditions of the pure SOA is unclear). This suggests that the heterogeneous freezing process for concentrated solution droplets below $-40^{\circ} \mathrm{C}$ may depend on the chemical species coating the dust material, the thickness of the coating, and the amount and size of dust material contained within the drop. It is possible that large droplet and emulsion experiments emphasize the impact of larger or multiple aerosol particles in contrast to single particle studies, but this topic will require further research. Again, interestingly, inhibition of freezing nucleation was not apparent in the mixed-phase regime above water saturation in the present studies.

\subsection{Comparison of dust results}

A direct comparison of the ice nucleation results presented in Fig. 1 with those presented in Figs. 2 and 3 is not appropriate since Figs. 2 and 3 represent $5 \%$ of the particles activating as 


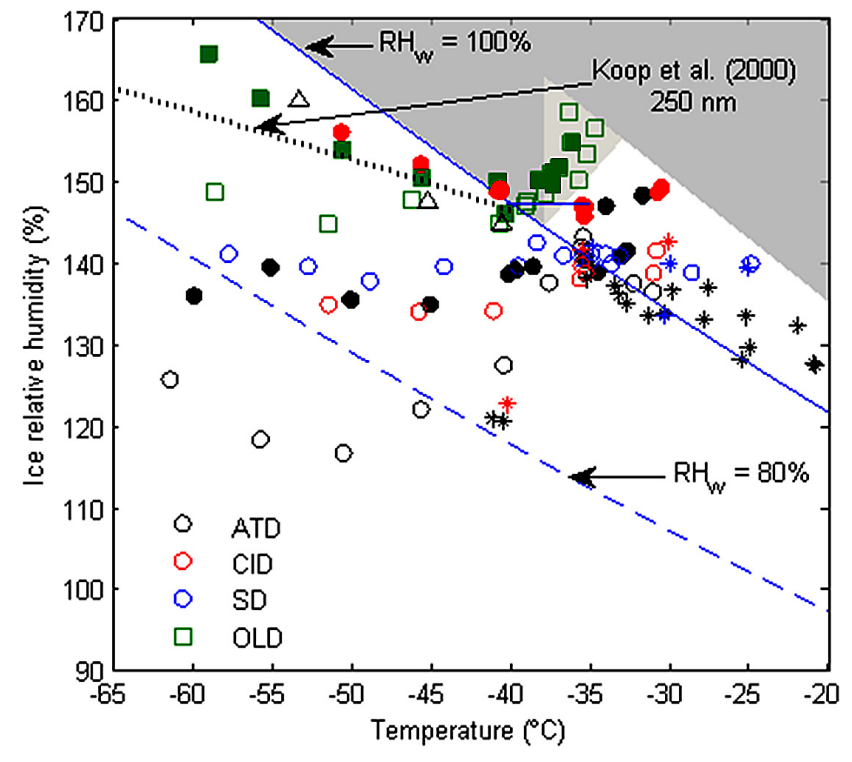

Fig. 5. Comparison of conditions for $1 \%$ activation of $200 \mathrm{~nm}$ particles as IN by ATD (black circles), CID (red circles), SD (blue circles), and Owens Lake Dust (OLD, green squares) reported from Koehler et al., (2007). Filled symbols represent those generated by atomization from aqueous suspension. Conditions for $1 \%$ of polydisperse aerosol as IN by ATD (black stars), CID (red stars) and SD (blue stars). Conditions for $1 \%$ activation of $250 \mathrm{~nm}$ coated ATD (black triangles). The dark gray shading indicates the region where droplets are known to be counted by the OPC in the CFDC systems. The light gray shading indicates the transition where the state of the particle counted by the OPC is ambiguous. Water saturation, $\mathrm{RH}_{w}=80 \%$ and the conditions for which $250 \mathrm{~nm}\left(\mathrm{NH}_{4}\right)_{2} \mathrm{SO}_{4}$ particles nucleate ice according to Koop et al. (2000) are indicated in the figure for reference.

IN (except for the polydisperse samples) and Fig. 1 is for $1 \%$ activation. However, the conditions supporting $1 \%$ activation of CID and SD can be determined for the $200 \mathrm{~nm}$ particles because there is little influence of the dry or haze particles on the OPC signal for these smallest particles studied. Figure 5 shows the conditions for which $1 \%$ of the $200 \mathrm{~nm}$ SD particles (blue circles), CID (red circles), and ATD (black circles) activated as IN. Also included on the figure are the conditions for which $1 \%$ of the polydisperse aerosol nucleated ice during the ICIS campaign (stars, colors indicating dust type, as for the $200 \mathrm{~nm}$ particles). For completeness, we have included the conditions for $1 \%$ activation on $250 \mathrm{~nm}$ coated ATD particles (black triangles) as well as on $200 \mathrm{~nm}$ Owens Lake Dust (OLD, green squares) particles from Koehler et al. (2007). Similar conditions were required for ice nucleation of the SD and CID at temperatures colder than $-36^{\circ} \mathrm{C}$, but it was observed that $\sim 6-18 \%$ higher $\mathrm{RH}_{i}$ conditions are required at a given temperature for the $\mathrm{CID}$ and $\mathrm{SD}$ than $\mathrm{ATD}$ for temperatures colder than $-36^{\circ} \mathrm{C}$. However all three dust types required nearly water saturated or supersaturated conditions at temperatures warmer than $-36^{\circ} \mathrm{C}$. The similarity in ice formation conditions for CID and SD particles observed in our studies is consistent with the findings of Schutz and Sebert (1987) that mineral dust compositions in North Africa are homogeneous for submicron particle sizes, however this does not necessarily account for the mixing state of the minerals and possible differences in the number of active sites per unit of surface area that may vary between samples. It is interesting that the observed shift from deposition nucleation to heterogeneous freezing occurs at approximately $-36^{\circ} \mathrm{C}$, similar to the temperature at which homogneous freezing occurs. It is unclear if there is a physical basis for this or if it is simply a coincidence. It is also unclear if the lower supersaturations required for ice formation on ATD, as compared to the North African region samples, are due to differences in chemical composition or if the milling process used in production of the ATD creates more active sites than are found on natural mineral dust aerosols. The OLD sample contained an appreciable amount of soluble material, and therefore it is not surprising that this sample required the highest $\mathrm{RH}_{i}$ values for ice nucleation at a given temperature. None of the samples exhibited ice nucleation above the $1 \%$ threshold at temperatures warmer than $-20^{\circ} \mathrm{C}$, for the sizes examined in either the CFDC or AIDA chamber during the ICIS campaign (DeMott et al., 2008; Möhler et al., 2008b).

Figure 5 highlights the clear distinction between the behaviors of dry-generated particles and those generated from atomization of aqueous suspensions (so called "wetgenerated", filled symbols, from Koehler, 2008) at temperatures colder than $-40^{\circ} \mathrm{C}$. Due to the small sample size of the SD available for these studies, no tests were run with SD in aqueous suspension. At temperatures colder than $-20^{\circ} \mathrm{C}$, the dry-generated particle types generally showed a size dependence. For example, the CID showed distinct $\mathrm{RH}_{i}$ values for ice nucleation as a function of size for temperatures below $-36^{\circ} \mathrm{C}$. This result is consistent with results found by Archuleta et al. (2005) for an Asian desert dust sample. At warmer temperatures this point is most apparent for the ATD. While the particles smaller than $400 \mathrm{~nm}$ lost ice the ability to nucleate ice rapidly for increasing temperature, the polydisperse samples containing larger aerosol exhibited ice nucleation near water saturation. A similar behavior is noted for the SD. For all dry-generated dust types, the freezing mode transitioned from deposition to condensation freezing at $\sim-36{ }^{\circ} \mathrm{C}$.

Wet-generated CID and OLD and coated dust particles, however, generally initiated ice formation at conditions similar to those required for homogeneous freezing of sulfates at temperatures colder than $36^{\circ} \mathrm{C}$. We expect that this indicates that when the particles contain sufficient soluble material to cover the particle surface, active sites are prevented from serving as deposition nucleation sites. Nucleation was observed at temperatures warmer than $\sim-36^{\circ} \mathrm{C}$, above the limit of homogeneous freezing, indicating that condensation freezing may still proceed, but may depend on the insoluble and soluble material (Möhler et al., 2008). It appears 
that soluble material, either present as a component of the dust, or deposited on the dust surface through gas phase reactions, acts to inhibit the active sites on the dust, so either the solution coating freezes homogeneously or the dust initiates freezing through immersion or condensation freezing at much higher $\mathrm{RH}_{i}$ than was observed for the uncoated ATD. This higher activation $\mathrm{RH}_{i}$ in some cases is indistinguishable from conditions for homogeneous freezing of the coatings. In contrast, the wet-generated ATD exhibited similar behavior to the other dry-generated dusts, although a higher $\mathrm{RH}_{i}$ was required for freezing of the wet-generated ATD than when dry-generated for temperatures colder than $-36^{\circ} \mathrm{C}$. This may be due to the very small soluble content of this dust type and the impact of its redistribution following atomization.

While the dry-generation method is expected to be more representative of dust particles in the atmosphere, Figure 5 stresses the importance of aerosol generation method in laboratory studies and could have implications to the impact of liquid cloud processing on the low temperature ice formation behavior of natural mineral dust particles.

\section{Atmospheric implications}

Heymsfield and Miloshevich (1995) parameterized threshold $\mathrm{RH}_{i}$ requirements as a function of temperature for cirrus formation. Dry-generated dust particles (which are expected to be more representative of those released to the atmosphere) nucleated ice at lower $\mathrm{RH}_{i}$ than the Heymsfield and Misoshevich expected requirements for most conditions with particle diameters $200 \mathrm{~nm}$ and larger. This is not surprising since those conditions were expected to be for homogeneous nucleation in the absence of many IN, but did not exclude possible heterogeneous mechanisms. Therefore, it can be expected that these particles would alter cold cloud formation compared to conditions that would exist with only background aerosol. While it may be hypothesized that most dust particles do not reach the upper troposphere in their pure state (Kärcher and Lohmann, 2003) or without previous cloud processing (Wiacek et al., 2010), their efficiency in nucleating ice at low $\mathrm{RH}_{i}$ makes even a small number concentration of pristine dust IN relevant to cloud formation. DeMott et al. (2003a) and Cziczo et al. (2004) found that dust particles examined off the coast of Florida during the CRYSTAL-FACE experiment were generally externally mixed with sea salt and other soluble particle types. Also, DeMott et al. (2003b) found that only about $25 \%$ of the examined dust particles (evaporated ice crystals) sampled from free tropospheric air on Mt. Werner, Colorado (elevation $3200 \mathrm{~m}$ ) contained measurable sulfate and organic material, thus the relevance of the pristine dust to the atmosphere must be considered.

As noted earlier, in cirrus clouds forming in situ at high altitudes, a small concentration of IN that activate at modest ice supersaturations can have a large impact on cloud particle size distributions, due to their rapid growth at ice supersaturated conditions at the expense of the liquid droplets (DeMott et al., 1997). At warmer temperatures, Lohmann and Diehl (2006), using their parameterization of heterogeneous ice nucleation, found that dust can have a significant impact on the liquid water path, cloud lifetime, precipitation rate and top of the atmosphere radiation. Further, they found significant differences in these properties if the dust was assumed to be composed of kaolinite or montmorillonite, two common mineral types found in atmospheric dust, due to small changes in the activation behavior between these species. However, these findings should be tempered by the conclusions of Eidhammer et al. (2009), who noted that this parameterization, as well as others, allow for an unrealistic proportion of dust to nucleate, which may influence their conclusions.

Kärcher and Lohmann (2003) found for a constant freezing threshold of $130 \% \mathrm{RH}_{i}$ at cirrus temperatures, similar to the conditions found for ice formation on the size-selected, dry-generated CID and SD dust particles, that ice particle concentrations were strongly dependent on updraft velocity. When updraft velocities were greater than $30 \mathrm{~cm} \mathrm{~s}^{-1}$, ice particle concentrations were about a factor of 2 higher than was found for homogeneous freezing only. At lower updraft velocities, large (up to a factor of 10) decreases in ice crystal concentration were observed. Our observations suggest that dust could potentially initiate ice formation at an even lower freezing threshold than $\mathrm{RH}_{i} \sim 130 \%$ (as found for ATD particles and is likely for supermicron CID and SD particles). As nucleated particles start to grow and deplete the water vapor in the atmosphere, the maximum saturation achieved in the cloud will be lowered and even lower ice crystal concentrations would result.

Nucleation rates given by classical heterogeneous nucleation theory are very strong functions of the ice supersaturation and contact angle. This gives rise to the threshold activation parameterizations like those used by Kärcher and Lohmann (2003). However for the observed mineral dust samples, nucleation occurred over a broad range of $\mathrm{RH}_{w}$ conditions, even for a size-selected aerosol flow. Figure 6 shows activation curves for dry generated CID versus $200 \mathrm{~nm}$ ammonium sulfate particles that freeze homogeneously at $-40^{\circ} \mathrm{C}$ in the CFDC. Each point is an average over ten seconds of data. The solid line is the homogeneous freezing representation for perfectly monodisperse ammonium sulfate as predicted from Koop et al. (2000). It is clear that the experimentally-observed activation by homogeneous freezing is a very steep function of $\mathrm{RH}_{w}$, and is well represented by the water activity based parameterization excepting the need to consider non-monodispersity of the aerosol and some unresolved CFDC factors that can limit the maximum fractions of hygroscopic particles activating by homogeneous freezing (DeMott et al., 2009a; Richardson et al., 2010). In contrast, activation of the dry-generated CID (and other dust 
samples) occurs over a broad span of $10-20 \% \mathrm{RH}_{w}$. Connolly et al. (2009) also noted that ice nucleation occurred for a wide range of ice saturation values in the AIDA chamber, consistent with the observations presented here. Similar shallow activation curves were observed by DeMott et al. (2003a) who measured IN concentrations on top of a mountain in Colorado (Storm Peak Laboratory) and found that at temperatures warmer than $-35^{\circ} \mathrm{C}$ (heterogeneous ice nucleation regime), the nucleated concentration increased much more slowly with increasing saturation ratio than for temperatures below $-36^{\circ} \mathrm{C}$, where homogeneous nucleation was likely the dominant mechanism of ice formation for the majority of ambient particles.

Activation was observed on a small fraction of the particles at temperatures as warm as $-15^{\circ} \mathrm{C}$ by some of samples (also see DeMott et al., 2010; Kanji et al., 2010; Möhler et al., 2008b). In the regime of temperatures warmer than $-36^{\circ} \mathrm{C}$, even small fractions $(<1 \%)$ of dust able to initiate the ice phase will be important for the shift from liquid to mixed-phase clouds and for impacting precipitation processes, depending on dust number concentrations. Min et al. (2009) used observations of a mesoscale convective system that was partially influenced by elevated dust concentrations and found large increases in ice crystal concentration, yielding smaller crystals and suppressing precipitation. It should also be noted that in this study we could not measure the role of contact freezing nucleation, which could be efficient under warmer temperature conditions. The impact from dust serving as CCN or GCCN must also be considered and has been discussed in Koehler et al. (2009). The impact of a low fraction of ice nucleating particles on warmer mixedphase clouds requires detailed modeling and is beyond the scope of this work.

Our measurements show that a dust particle which acquires a coating requires higher relative humidities at the same temperature to nucleate ice with the same efficiency below $-36{ }^{\circ} \mathrm{C}$. These particles often initiated the ice phase at similar conditions as are found for pure soluble particles (Koop et al., 2000), and so may not dramatically impact the generation of cold (e.g., cirrus) clouds in the same manner as a relatively unprocessed particle. At warmer temperatures, for which water supersaturation was required for freezing, the SOA did not appear to have an influence in the few experiments performed. Therefore, the impact of the dust on cold cloud formation may depend on the way freshly emitted dust ages in the atmosphere. Processes in which a dust plume mixes with hygroscopic material, such as from an anthropogenically polluted airmass or airmasses over a large forest which contain hygroscopic secondary organic aerosol, may condense onto dust thereby reducing its ice nucleation activity at very low temperatures. However, these particles may be readily available to serve as immersion or condensation nuclei as well as CCN and/or GCCN and thereby have impacts on warm and mixed-phase clouds.

\section{Conclusions}

Ice nucleation behavior of three mineral dust samples was investigated. A mineral dust surrogate, Arizona Test Dust, was found to require the lowest $\mathrm{RH}_{i}$ conditions to initiate ice formation for $T<-40^{\circ} \mathrm{C}$; $\mathrm{RH}_{i}$ values for ice nucleation were at least $10 \%$ lower for Arizona Test Dust than for any other investigated sample. However, ice formation on $1 \%$ of the particles at temperatures warmer than $\sim-25^{\circ} \mathrm{C}$ was only observed for the polydisperse dust sample, indicating the strong size dependence of the required temperature for a given ice active fraction. This implies a rather strong temperature dependence of ice active fraction for a certain size or size distribution of dust particles, as shown in DeMott et al. (2010).

Two samples from the Saharan region, collected outside Cairo, Egypt and on the Canary Island, Lanzarote, were found to have similar IN activity, although the samples were collected more than $4000 \mathrm{~km}$ apart. These particles were able to initiate the ice phase at $\mathrm{RH}_{i}$ values much lower than required for homogeneous freezing and the Saharan region dusts exhibited a dependence of ice initiation on particle size in the cirrus temperature regime. Larger particles contained within the polydisperse aerosol streams were observed to freeze at a level representing $1 \%$ of all particles at temperatures as warm as $-20^{\circ} \mathrm{C}$, a trend which appears to continue to warmer temperatures for larger dust particles (Salam et al., 2006; Kanji and Abbatt, 2006; Knopf and Koop, 2006) and for lower frozen fractions (DeMott et al., 2010). It is uncertain if the efficiency of ice nucleation by the ATD particles is due to differences in particle composition between this sample and the natural dust samples, or if the milling procedure used to produce the small particle diameters characteristic of this sample produced very efficient active sites, which might not be representative of dust in the atmosphere.

Dry-generated Arizona Test dust particles were coated with secondary organic material formed via ozone oxidation of $\alpha$-pinene. It was found that these particles required similar conditions to initiate ice formation as are required for homogeneous freezing of soluble particles in the cirrus temperature regime. These coated particles, however, appeared to freeze heterogeneously at temperatures warmer than which homogeneous freezing occurs through the condensation freezing mode. The representativeness of the SOA to coatings that would occur in the atmosphere remains as an uncertainty for future study.

Ice crystal formation by mineral dust does not occur over a sharply defined range of $\mathrm{RH}_{w}$, as observed for pure soluble particles, such as ammonium sulfate. Typically, at a given temperature in the cirrus temperature regime, ice nucleation occurred over a range of $15-30 \% \mathrm{RH}_{w}$, whereas ammonium sulfate particles are mostly activated by homogeneous freezing over a range of only $2-4 \% \mathrm{RH}_{w}$. These results indicate that in numerical model simulations for which mineral dust is treated, all particles should not activate ice formation in 
a nearly step function, as this does not represent the behavior of the best present surrogates we have for natural dust areosols. Simulations may otherwise activate too many ice crystals, leading to overestimates of changes in the cloud microphysics.

The ice nucleation data presented indicates that these particles can impact cloud development by potentially limiting the peak supersaturation in a cirrus cloud by depleting water vapor and changing ice crystal concentrations. These changes can lead to dramatic changes in the radiative properties of the clouds and can potentially alter cloud lifetimes (DeMott et al., 1997). In the warmer (mixed-phase) cloud regime, water saturation becomes a requirement for significant ice formation. Nevertheless, even small fractions of dust particles freezing can impact cloud and precipitation development, so the implication from studies that larger dust particles can freeze in at progressively warmer temperatures deserves further quantitative investigation.

Acknowledgements. We thank Hans Moosmüller for providing the Canary Island dust for use in studies at Colorado State University. We thank Margaret Tolbert for loaning us the fluidized bed generator. This material is based on work supported by the National Science Foundation under grants ATM 0436196, ATM-0521643 and ATM-0611936. K. Koehler gratefully acknowledges support from the NASA Graduate Researchers Program. Karlsruhe Institute of Technology provided funding during ICIS-2007 for the facility infrastructure within the Helmholtz Research Programme "Atmosphere and Climate". We gratefully acknowledge skillful support from the AIDA team for organizational issues and instrument setup during the ICIS-2007 experiments.

Edited by: D. J. Cziczo

\section{References}

Alpert, P. and Reisin, T.: An Early Winter Polar Air-Mass Penetration To The Eastern Mediterranean, Mon. Weather Rev., 114, 1411-1418, 1986.

Alpert, P. and Ganor, E.: Sahara mineral dust measurements from TOMS: Comparison to surface observations over the Middle East for the extreme dust storm, March 14-17, 1998, J. Geophys. Res.Atmos., 106, 18275-18286, 2001.

Ansmann, A., Tesche, M., Althausen, D., Muller, D., Seifert, P., Freudenthaler, V., Heese, B., Wiegner, M., Pisani, G., Knippertz, P., and Dubovik, O.: Influence of Saharan dust on cloud glaciation in southern Morocco during the Saharan Mineral Dust Experiment, J. Geophys. Res.-Atmos., 113, D04210, doi:10.1029/2007jd008785, 2008.

Ansmann, A., Tesche, M., Seifert, P., Althausen, D., Engelmann, R., Fruntke, J., Wandinger, U., Mattis, I., and Muller, D.: Evolution of the ice phase in tropical altocumulus: SAMUM lidar observations over Cape Verde, J. Geophys. Res.-Atmos., 114, D17208, doi:10.1029/2008jd011659, 2009.

Archuleta, C. M., DeMott, P. J., and Kreidenweis, S. M.: Ice nucleation by surrogates for atmospheric mineral dust and mineral dust/sulfate particles at cirrus temperatures, Atmos. Chem. Phys., 5, 2617-2634, doi:10.5194/acp-5-2617-2005, 2005.
Bassett, D. R., Boucher, E. A., and Zettlemo, A. C.: Adsorption Studies On Ice-Nucleating Substrates - Hydrophobed Silicas And Silver Iodide, J. Coll. Interf. Sci., 34, 436-446, 1970.

Connolly, P. J., Mohler, O., Field, P. R., Saathoff, H., Burgess, R., Choularton, T., and Gallagher, M.: Studies of heterogeneous freezing by three different desert dust samples, Atmos. Chem. Phys., 9, 2805-2824, doi:10.5194/acp-9-2805-2009, 2009.

Criado, C. and Dorta, P.: An unusual 'blood rain' over the Canary Islands (Spain). The storm of January 1999, J. Arid Environ., 55, 765-783, 2003.

Cziczo, D. J., Murphy, D. M., Hudson, P. K., and Thomson, D. S.: Single particle measurements of the chemical composition of cirrus ice residue during CRYSTAL-FACE, J. Geophys. Res.Atmos., 109, D04201, doi:10.1029/2003JD004032, 2004.

D'Alemeida, G. A.: A model for Saharan dust transport, J. Clim. Appl. Meterol., 25, 903-916, 1986.

DeMott, P. J., Rogers, D. C., and Kreidenweis, S. M.: The susceptibility of ice formation in upper tropospheric clouds to insoluble aerosol components, J. Geophys. Res.-Atmos., 102, 1957519584, 1997.

DeMott, P. J., Cziczo, D. J., Prenni, A. J., Murphy, D. M., Kreidenweis, S. M., Thomson, D. S., Borys, R., and Rogers, D. C.: Measurements of the concentration and composition of nuclei for cirrus formation, Proc. Natl. Acad. Sci. USA, 100, 14655-14660, 2003a.

DeMott, P. J., Sassen, K., Poellot, M. R., Baumgardner, D., Rogers, D. C., Brooks, S. D., Prenni, A. J., and Kreidenweis, S. M.: African dust aerosols as atmospheric ice nuclei, Geophys. Res. Lett., 30, 1732, doi:10.1029/2003GL017410, 2003b.

DeMott, P. J., Möhler, O. P., Stetzer, O., Murakami, M., Bundke, U., Klein, H., Kanji, Z., Cotton, R., Jones, H., Leisner, T., Cziczo, D., Petters, M. D., Prenni, A. J., Kreidenweis, S. M., Schnaiter, M., Schön, R., Saathoff, H., Wagner, R., Sierau, B., Nicolet, M., Lohmann, U., Gallavardin, S., Saito, A., Nillius, B., Bingemer, H., Abbatt, J., Bowels, J., Targino, A., Dorsey, J., Ardon, K., Levin, Z., Ganor, E., Georgakopoulos, D. G., and Vali, G.: The Fourth International Ice Nucleation Workshop (ICIS-2007): Objectives and preliminary resuls, 15th International Conference on Clouds and Precipitation, Cancun, Mexico, 2008.

DeMott, P. J., Petters, M. D., Prenni, A. J., Carrico, C. M., Kreidenweis, S. M., Collett, J. L., and Moosmuller, H.: Ice nucleation behavior of biomass combustion particles at cirrus temperatures, J. Geophys. Res.-Atmos., 114, D16205 doi:10.1029/2009jd012036, 2009a.

DeMott, P. J., Sassen, K., Poellot, M. R., Baumgardner, D., Rogers, D. C., Brooks, S. D., Prenni, A. J., and Kreidenweis, S. M.: Correction to "African dust aerosols as atmospheric ice nuclei", Geophys. Res. Lett., 36, L07808, doi:10.1029/2009GL037639, 2009b.

DeMott, P. J., O. Möhler, O. Stetzer, M. Murakami, T. Leisner, U. Bundke, H. Klein, Z. Kanji, R. Cotton, H. Jones, M. Petters, A. Prenni, S. Benz, M. Brinkmann, D. Rzesanke, H. Saathoff, M. Nicolet, S. Gallavardin, A. Saito, B. Nillius, H. Bingemer, J. Abbatt, K. Ardon, Z. Levin, E. Ganor, Georgakopoulos, D. G., and Vali, G.: Resurgence in ice nucleation research, Bull. Amer. Meteor. Soc., submitted, 2010.

Docherty, K. S., Wu, W., Lim, Y. B., and Ziemann, P. J.: Contributions of organic peroxides to secondary aerosol formed from reactions of monoterpenes with O-3, Environ. Sci. Technol., 39, 
4049-4059, 2005.

Eidhammer, T., DeMott, P. J., and Kreidenweis, S. M.: A comparison of heterogeneous ice nucleation parameterizations using a parcel model framework, J. Geophys. Res.-Atmos., 114, D06202, doi:10.1029/2008jd011095, 2009.

Field, P. R., Möhler, O., Connolly, P., Kramer, M., Cotton, R., Heymsfield, A. J., Saathoff, H., and Schnaiter, M.: Some ice nucleation characteristics of Asian and Saharan desert dust, Atmos. Chem. Phys., 6, 2991-3006, doi:10.5194/acp-6-2991-2006, 2006.

Giles, J.: Climate science: The dustiest place on on Earth, Nature, 434, 816-819, 2005.

Goudie, A. S. and Middleton, N. J.: Saharan dust storms: nature and consequences, Earth-Science Reviews, 56, 179-204, 2001.

Heald, C. L., Jacob, D. J., Turquety, S., Hudman, R. C., Weber, R. J., Sullivan, A. P., Peltier, R. E., Atlas, E. L., de Gouw, J. A., Warneke, C., Holloway, J. S., Neuman, J. A., Flocke, F. M., and Seinfeld, J. H.: Concentrations and sources of organic carbon aerosols in the free troposphere over North America, J. Geophys. Res.-Atmos., 111, D23S47, doi:10.1029/2006JD007705, 2006.

Heymsfield, A. J., and Miloshevich, L. M.: Relative humidity and temperature influences on cirrus formation and evolution: Observations from wave clouds and FIRE II, J. Atmos. Sci., 52, 4302-4326, 1995.

Kanji, Z. A., P. J. DeMott, O. Mohler, and J. P. D. Abbatt, Results from the University of Toronto continuous flow diffusion chamber (UT-CFDC) at the international workshop for comparing ice nucleation measuring systems (ICIS 2007). Atmos. Chem. Phys. Discuss., 10, 20857-20886, doi:10.5194/acp-1020857-2010, 2010.

Kanji, Z. A. and Abbatt, J. P. D.: Laboratory studies of ice formation via deposition mode nucleation onto mineral dust and nhexane soot samples, J. Geophys. Res.-Atmos., 111, D16204, doi:10.1029/2005jd006766, 2006.

Kärcher, B. and Lohmann, U.: A parameterization of cirrus cloud formation: Heterogeneous freezing, J. Geophys. Res.-Atmos., 108, 4402, doi:10.1029/2002JD003220, 2003.

Knopf, D. A. and Koop, T.: Heterogeneous nucleation of ice on surrogates of mineral dust, J. Geophys. Res.-Atmos., 111, D12201, doi:10.1029/2005jd006894, 2006.

Koehler, K. A., Kreidenweis, S. M., DeMott, P. J., Prenni, A. J., and Petters, M. D.: Potential impact of Owens (dry) Lake dust on warm and cold cloud formation, J. Geophys. Res.-Atmos., 112, D12210, doi:10.1029/2007JD008413, 2007.

Koehler, K. A.: The Impact of Natural Dust Aerosol on Warm and Cold Cloud Formation, Atmospheric Science, Colorado State University, Fort Collins, 207 pp., 2008.

Koehler, K. A., Kreidenweis, S. M., DeMott, P. J., Petters, M. D., Prenni, A. J., and Carrico, C. M.: Hygroscopicity and cloud droplet activation of mineral dust aerosol, Geophys. Res. Lett., 36, L08805, doi:10.1029/2009g1037348, 2009.

Koop, T., Luo, B. P., Tsias, A., and Peter, T.: Water activity as the determinant for homogeneous ice nucleation in aqueous solutions, Nature, 406, 611-614, 2000.

Kubilay, N., Nickovic, S., Moulin, C., and Dulac, F.: An illustration of the transport and deposition of mineral dust onto the eastern Mediterranean, Atmos. Environ., 34, 1293-1303, 2000.

Lin, R. F., Starr, D. O., DeMott, P. J., Cotton, R., Sassen, K., Jensen, E., Karcher, B., and Liu, X. H.: Cirrus Parcel Model Compari- son Project. Phase 1: The critical components to simulate cirrus initiation explicitly, J. Atmos. Sci., 59, 2305-2329, 2002.

Linke, C., Mohler, O., Veres, A., Mohacsi, A., Bozoki, Z., Szabo, G., and Schnaiter, M.: Optical properties and mineralogical composition of different Saharan mineral dust samples: a laboratory study, Atmos. Chem. Phys., 6, 3315-3323, doi:10.5194/acp-63315-2006, 2006.

Lohmann, U. and Diehl, K.: Sensitivity studies of the importance of dust ice nuclei for the indirect aerosol effect on stratiform mixedphase clouds, J. Atmos. Sci., 63, 968-982, 2006.

Mahowald, N. M. and Kiehl, L. M.: Mineral aerosol and cloud interactions, Geophys. Res. Lett., 30, 1475, doi:10.1029/2002GL016762, 2003.

Min, Q. L., Li, R., Lin, B., Joseph, E., Wang, S., Hu, Y., Morris, V., and Chang, F.: Evidence of mineral dust altering cloud microphysics and precipitation, Atmos. Chem. Phys., 9, 3223-3231, doi:10.5194/acp-9-3223-2009, 2009.

Möhler, O., Field, P. R., Connolly, P., Benz, S., Saathoff, H., Schnaiter, M., Wagner, R., Cotton, R., Kramer, M., Mangold, A., and Heymfield, A. J.: Efficiency of the deposition mode ice nucleation on mineral dust particles, Atmos. Chem. Phys., 6, 30073021, doi:10.5194/acp-6-3007-2006, 2006.

Möhler, O., Benz, S., Saathoff, H., Schnaiter, M., Wagner, R., Schneider, J., Walter, S., Ebert, V., and Wagner, S.: The effect of organic coating on the heterogeneous ice nucleation efficiency of mineral dust aerosols, Environ. Res. Lett., 3, 025007, doi:10.1088/1748-9326/3/2/025007, 2008a.

Möhler, O. P., DeMott, P. J., Stetzer, O., and Team, I.-- The Fourth International Ice Nucleation Workshop ICIS-2007: Methods and Instruments, 15th International Conference on Clouds and Precipitation, Cancun, Mexico, 2008b.

Murray, B. J., Wilson, T. W., Broadley, S. L., and Wills, R. H.: Heterogeneous freezing of water droplets containing kaolinite and montmorillonite particles, Atmospheric Chemistry and Physics Discussions, 10, 9695-9729, doi:10.5194/acpd-10-9695-2010, 2010a.

Murray, B. J., Wilson, T. W., Dobbie, S., Cui, Z. Q., Al-Jumur, S., Mohler, O., Schnaiter, M., Wagner, R., Benz, S., Niemand, M., Saathoff, H., Ebert, V., Wagner, S., and Karcher, B.: Heterogeneous nucleation of ice particles on glassy aerosols under cirrus conditions, Nature Geosci., 3, 233-237, doi:10.1038/ngeo817, 2010b.

Petters, M. D., Parsons, M. T., Prenni, A. J., DeMott, P. J., Kreidenweis, S. M., Carrico, C. M., Sullivan, A. P., McMeeking, G. R., Levin, E., Wold, C. E., Collett, J. L., and Moosmuller, H.: Ice nuclei emissions from biomass burning, J. Geophys. Res.-Atmos., 114, D07209, doi:10.1029/2008jd011532, 2009a.

Petters, M. D., Wex, H., Carrico, C. M., Hallbauer, E., Massling, A., McMeeking, G. R., Poulain, L., Wu, Z., Kreidenweis, S. M., and Stratmann, F.: Towards closing the gap between hygroscopic growth and activation for secondary organic aerosol - Part 2: Theoretical approaches, Atmos. Chem. Phys., 9, 3999-4009, doi:10.5194/acpd-9-3999-2009, 2009b.

Poulain, L., Wu, Z., Petters, M. D., Wex, H., Hallbauer, E., Wehner, B., Massling, A., Kreidenweis, S. M., and Stratmann, F.: Towards closing the gap between hygroscopic growth and $\mathrm{CCN}$ activation for secondary organic aerosols - Part 3: Influence of the chemical composition on the hygroscopic properties and volatile fractions of aerosols, Atmos. Chem. Phys., 10, 3775- 
3785, doi:10.5194/acpd-10-3775-2010, 2010.

Pratt, K. A., DeMott, P. J., French, J. R., Wang, Z., Westphal, D. L., Heymsfield, A. J., Twohy, C. H., Prenni, A. J., and Prather, K. A.: In situ detection of biological particles in cloud ice-crystals, Nature Geosci., 2, 397-400, doi:10.1038/ngeo521, 2009.

Prenni, A. J., Siefert, R. L., Onasch, T. B., Tolbert, M. A., and DeMott, P. J.: Design and characterization of a fluidized bed aerosol generator: A source for dry, submicrometer aerosol, Aerosol Sci. Technol., 32, 465-481, 2000.

Prenni, A. J., Petters, M. D., Faulhaber, A., Carrico, C. M., Ziemann, P. J., Kreidenweis, S. M., and DeMott, P. J.: Heterogeneous ice nucleation measurements of secondary organic aerosol generated from ozonolysis of alkenes, Geophys. Res. Lett., 36, L06808, doi:10.1029/2008g1036957, 2009.

Pruppacher, H. R. and Klett, J. D.: Microphysics of Clouds and Precipitation, 2 ed., Kluwer Academic Publishers, Dordrecht, The Netherlands, 954 pp., 1997.

Richardson, M.: Making Real Time Measurements of Ice Nucleation at Upper Tropospheric Temperatures: Extending the Capabilities of the Continuous Flow Diffusion Chamber, Ph.D., Atmospheric Science, Colorado State University, Fort Collins, 316 pp., 2009.

Richardson, M. S., DeMott, P. J., Kreidenweis, S. M., Petters, M. D., and Carrico, C. M.: Observations of ice nucleation by ambient aerosol in the homogeneous freezing regime, Geophys. Res. Lett., 37, L04806, doi:10.1029/2009g1041912, 2010.

Rogers, D. C.: Development of a continuous flow thermal gradient diffusion chamber for ice nucleation studies, Atmos. Res., 22, 149-181, 1988.

Rogers, D. C., DeMott, P. J., Kreidenweis, S. M., and Chen, Y. L.: A continuous-flow diffusion chamber for airborne measurements of ice nuclei, J. Atmos. Ocean. Technol., 18, 725-741, 2001.

Salam, A., Lohmann, U., Crenna, B., Lesins, G., Klages, P., Rogers, D., Irani, R., MacGillivray, A., and Coffin, M.: Ice nucleation studies of mineral dust particles with a new continuous flow diffusion chamber, Aerosol Sci. Technol., 40, 134-143, 2006.

Sassen, K.: Indirect climate forcing over the western US from Asian dust storms, Geophys. Res. Lett., 29, 1465, doi:10.1029/2001GL014051, 2002.

Sassen, K., DeMott, P. J., Prospero, J. M., and Poellot, M. R.: Saharan dust storms and indirect aerosol effects on clouds: CRYSTAL-FACE results, Geophys. Res. Lett., 30, 1633, doi:10.1029/2003GL017371, 2003.

Schütz, L. and Sebert, M.: Mineral aerosols and source identification, J. Aerosol Sci., 18, 1-10, 1987.

Stith, J. L., Ramanathan, V., Cooper, W. A., Roberts, G. C., DeMott, P. J., Carmichael, G., Hatch, C. D., Adhikary, B., Twohy, C. H., Rogers, D. C., Baumgardner, D., Prenni, A. J., Campos, T., Gao, R., Anderson, J., and Feng, Y.: An overview of aircraft observations from the Pacific Dust Experiment campaign, J. Geophys. Res.-Atmos., 114, D05207, doi:10.1029/2008jd010924, 2009.
Swap, R., Ulanski, S., Cobbett, M., and Garstang, M.: Temporal and spatial characteristics of Saharan dust outbreaks, J. Geophys. Res., 101, 4205-4220, 1996.

Twohy, C. H., Kreidenweis, S. M., Eidhammer, T., Browell, E. V., Heymsfield, A. J., Bansemer, A. R., Anderson, B. E., Chen, G., Ismail, S., DeMott, P. J., and Van den Heever, S. C.: Saharan dust particles nucleate droplets in eastern Atlantic clouds, Geophys. Res. Lett., 36, L01807, doi:10.1029/2008gl035846, 2009.

Uno, I., Eguchi, K., Yumimoto, K., Takemura, T., Shimizu, A., Uematsu, M., Liu, Z. Y., Wang, Z. F., Hara, Y., and Sugimoto, N.: Asian dust transported one full circuit around the globe, Nat. Geosci., 2, 557-560, doi:10.1038/ngeo583, 2009.

Washington, R., Todd, M. C., Lizcano, G., Tegen, I., Flamant, C., Koren, I., Ginoux, P., Engelstaedter, S., Bristow, C. S., Zender, C. S., Goudie, A. S., Warren, A., and Prospero, J. M.: Links between topography, wind, deflation, lakes and dust: The case of the Bodele Depression, Chad, Geophys. Res. Lett., 33, L09401, doi:10.1029/2006GL025827, 2006.

Welti, A., Luond, F., Stetzer, O., and Lohmann, U.: Influence of particle size on the ice nucleating ability of mineral dusts, Atmos. Chem. Phys., 9, 6705-6715, doi:10.5194/acp-9-6705-2009, 2009.

Wex, H., Petters, M. D., Carrico, C. M., Hallbauer, E., Massling, A., McMeeking, G. R., Poulain, L., Wu, Z., Kreidenweis, S. M., and Stratmann, F.: Towards closing the gap between hygroscopic growth and activation for secondary organic aerosol: Part 1-Evidence from measurements, Atmos. Chem. Phys., 9, 39873997, doi:10.5194/acp-8-6365-2009, 2009.

Wiacek, A. and Peter, T.: On the availability of uncoated mineral dust ice nuclei in cold cloud regions, Geophys. Res. Lett., 36, L17801, doi:10.1029/2009g1039429, 2009.

Wiacek, A., Peter, T., and Lohmann, U.: The potential influence of Asian and African mineral dust on ice, mixed-phase and liquid water clouds, Atmos. Chem. Phys., 10, 8649-8667, doi:10.5194/acp-10-8649-2010, 2010.

Zimmerman, F., S., W., Schutz, L., Hofmann, L., Ebert, M., Kandler, K., and Worringen, A.: Ice Nucleation Properties of the Most Abundant Mineral Dust Phases, J. Geophys. Res., 113, D23204, doi:10.1029/2008JD010655, 2008.

Zobrist, B., Marcolli, C., Peter, T., and Koop, T.: Heterogeneous ice nucleation in aqueous solutions: the role of water activity, $\mathrm{J}$ Phys. Chem. A, 112, 3965-3975, doi:10.1021/jp7112208, 2008.

Zuberi, B., Bertram, A. K., Cassa, C. A., Molina, L. T., and Molina, M. J.: Heterogeneous nucleation of ice in $\left(\mathrm{NH}_{4}\right)(2) \mathrm{SO}_{4}-\mathrm{H}_{2} \mathrm{O}$ particles with mineral dust immersions, Geophys. Res. Lett., 29, 1504, doi:10.1029/2001g1014289, 2002. 